\title{
Toward an Ontology of Strategy in an Enterprise Context
}

Neil Kemp, NKA Inc., Canada

\begin{abstract}
What is meant by "strategy" and what concepts are involved in its creation are not well understood, and there is significant inconsistency in the way they are all used. It was hypothesised that current tools and techniques for ontology development and semantic analysis could be effectively applied to understand better what is meant by the term strategy and understand their nature and relationships. A literature review was conducted to identify how practitioners and academia view the subject, and the results organised using structured analysis. The result is a more complete, internally consistent view of the features of strategy definition. By applying structured analysis, the components and relationships used to form strategy and therefore the requisite structure of strategy in the enterprise context are uncovered. In this way, the specification that makes up a strategy is better understood using conceptual and systems dynamics models. In this way, the nature and relationships necessary and sufficient to describe the multiple dimensions of strategy are exposed.
\end{abstract}

\section{KEYWORDS}

Business Architecture, Conceptual Model, Conceptual Structures, Strategy Levels, Strategy Meta-Model, Strategy Modelling, Structured Analysis, Systems Dynamics

\section{INTRODUCTION}

Strategy is different from planning or strategic planning in that the former consists in expositions of activity, while the latter is a synthesis of choices (Jomini, 1854; Porter, 1996). For this reason, the nature of decision making, action, and insight required to form a strategy, and the nature of a plan is radically different.

Much has been written on strategy formation, implementation, and execution, on the history and evolution of strategy and of how the business has embraced or has needed to embrace military thinking on the subject. Writers such as General Carl von Clausewitz (2019) and Colonel John Boyd (Hammond, 2004) have covered the evolution in military thinking, while Ohmae 1988), Mintzberg, 2007) Porter 1986), and many others have put forward ideas on the nature of strategy for business and its formation in this context. All without making a case for what strategy "is," or what the necessary and sufficient parts of strategy are, makes it extremely difficult to build any shared understanding of how to evaluate strategy or test for the completeness of strategic thinking.

The view of strategy taken in this analysis is not about methods or the process for the formation of strategy, nor about developing positions for an enterprise in pursuit of its future. It is not about anything to do with any school of strategy or anything that anyone does with the strategy. This view is about defining the requisite content of strategy. In other words, instead of trying to resolve the

\section{DOI: 10.4018/IJBSA.288040}

This article published as an Open Access article distributed under the terms of the Creative Commons Attribution License (http://creativecommons.org/licenses/by/4.0/) which permits unrestricted use, distribution, and production in any medium, provided the author of the original work and original publication source are properly credited. 
confusion within the strategy, the authors seek to find the fundamental features and interactions within strategy and its relationship with the design or architecture of the enterprise. Thus, this paper may lead to understanding the essential aspects of a strategy. Similarly, when physicists use particle accelerators to find the elementary subatomic particles and understand the dynamics and structure of matter, space, and time, the authors can smash the concept apart to find its constituent pieces and improve their understanding of the essence of strategy.

\section{BACKGROUND}

Strategy is distinct from two other concepts that also have their roots in war. For the Greeks and Byzantines, "strategy" or stratēgia episteme loosely meant "what generals think about" or, "the knowledge of generals" (Luttwak, 2002, p. 267), that is about what it takes to win a war, whereas "tactics" referred to the effective use of resources, that is what is involved in the orderly organisation and manoeuvre of troops to win a battle (Freedman, 1985. The bridging concept "operational planning" (Simpson \& Weiner, 1989) is often included to address the mapping required to align what happened in the world of strategic and the world of tactics. (Porter 1979), Ashcroft (1965), and of course, Ohmae (1988) integrated these ideas into business thinking.

While there is not much clarity in the historical writing on this subject (Marston \& Leahy, 2016), a current definition of (military) strategy sees it as follows:

A prudent idea or set of ideas for employing national power instruments in a synchronised and integrated fashion to achieve theatre, national, and/or multinational objectives. (U.S. Joint Chiefs of Staff, 2013, p.251)

Many thinkers have put forward ideas about strategy and strategy formation. However, a representative list might typically include Sun Tzu's The Art of War", (Sun Tzu, c 500) Niccolò Machiavelli's “The Prince (Machiavelli', 1513), von Clausewitz's “On War" (von Clausewitz's “On War”, (von Clausewitz, 2019), and Boyd's OODA Loop (Boyd, 1986). Within the business domain, such thinkers include H. Igor Ansoff, Mintzberg et al. (2005), and Ohmae (1988). For the most part, these thinkers emphasised what can be called "tricks of the trade" or "best practices" for winning a contest of minds (Hammond, 2004) These writings, whether in the context of business or war, deal with patterns of strategy formation and forms of strategy which are presented as schools of thought (Mintzberg et al., 2005), aphorisms (Sun Tzu c 500) studies (Brown \& Eisenhardt, 1998; Mintzberg, 2007; Ralston \& Wilson, 2006) or themes (Boyd, 1986). The challenge is that aphorisms and patterns of strategic moves that suggest a course of action tell nothing about what a well-formed strategy should contain. While the "blue ocean strategy" (Kim \& Mauborgne, 2005) or advocates of growth strategy, cost leadership strategy, differentiation strategy, cost focus strategy or differentiation focus strategy put forward notions of what the desired or result strategy execution might be, there is no consideration of whether the proposed strategy or strategic plan is complete. Indeed, many efforts to develop strategy may represent a couple of a firm's priorities and choices; they do not form a coherent strategy when considered either in terms of their insight or lack the features to be a strategy (Vermeulen, 2017).

What further compounds the challenge of parsing these questions is that all tiers' features and insights may affect all other tiers. For example, in World War I the introduction of weapons that allowed small units of infantry to stop a massed cavalry charge (i.e., the machine gun) changed the tactical circumstances, led in turn to new doctrine, and changed to the way operational planning was conducted and then to a shift in strategy, from one of attrition to one based on manoeuvre (i.e., destruction of the combat power of the enemy's armed forces through manoeuvre). Similarly, digital technologies have become disruptive to business, and suitable learning has not fully determined how to realise value from them entirely or to counter or exploit their effects. 
While much of what happens with the process of strategy formation and execution is emergent, particularly in the face of shifting environments, and as businesses engage in a "red queen's race" (Carroll, 2015) of move and countermove, the following points are generally agreed or accepted:

1. Strategy addresses the holistic description of the" "mind of the decision-maker," what means must be available or made available, and what the ways through which the desired ends to be achieved are to be.

2. Strategy is part of decision making (Porter, 1996) and can be classified into planning levels.

3. Strategy must identify and define the resources, structures, and behaviours necessary to balance stakeholders' needs while operating as a going concern with the wherewithal to achieve a defined vision in a specified context (ISACA, 2019). As a result, ends, means, and ways are themselves composite, that is, each has attributes that are independent of their unique name (Finkelstein, 1989).

4. The interaction and interplay between all the components of strategy must be synchronised, aligned, and coherent to each other, to make the strategy coherent (Boyd, 1986).

5. Strategy must balance the uncertainty to which it responds with the risk or uncertainty or returns it creates (International Organization for Standardization [ISO], 2018).

6. The integration of a strategy takes place through an approach that synthesises the properties and relationships between all elements of which it is composed (Jomini, 1854).

7. In competitive situations, a strategy must account for and seek differentiation within the market (Collis, 2008).

8. Within the execution process, the ability to account for time is paramount against an objective or in a perspective or viewpoint (Boyd, 1995).

The astute observer may note that none of these views includes the performance measures needed to implement or execute strategy. While measurement is important within the application of strategy, as it is not essential to strategy's nature, it is not included.

While each of these factors forms a view of an aspect of strategy, the final view requires, first, that the needs of each view be satisfied and, second, that all views be integrated.

Each of these distinctions can be addressed using discipline and structured methods and tools that subject each to appropriate analysis, thereby exposing relevant details and understanding and then harmonising the results into a unified view of what "strategy" is.

\section{Resolution}

Understanding the set of concepts and categories within strategy, their properties, and their relations is essential in forming a clear understanding of strategy's nature. (Arp, 2015) A conceptual model or ontology does this (Object Management Group [OMG], 2015). A conceptual model is a graphical language for visualising, specifying, and constructing an area's logic under investigation (OMG, 2015). Graphically, a conceptual model provides a visual representation of the countable nouns embodying the kinds of things of significance in the domain and relationship assertions between pairs of concepts. Thus, a conceptual model aims to express the meaning of terms and concepts domain experts use to discuss the problem and find the correct relationships between different concepts (OMG, 2015). They were using conceptual models to clarify the meaning of ambiguous terms aids in ensuring that problems with different interpretations of the terms and concepts can be exposed and eliminated. For these reasons, the conceptual model is highly suited to gathering insight to explore and organise the concepts used to describe the enterprise teleology features.

The result of this process is a representation of the things (whether concrete or abstract) that can be named and whose members or instances can be counted (Spewak, 1992).

The foundational building blocks of the ontology, its components, are then created from the literature review results. 


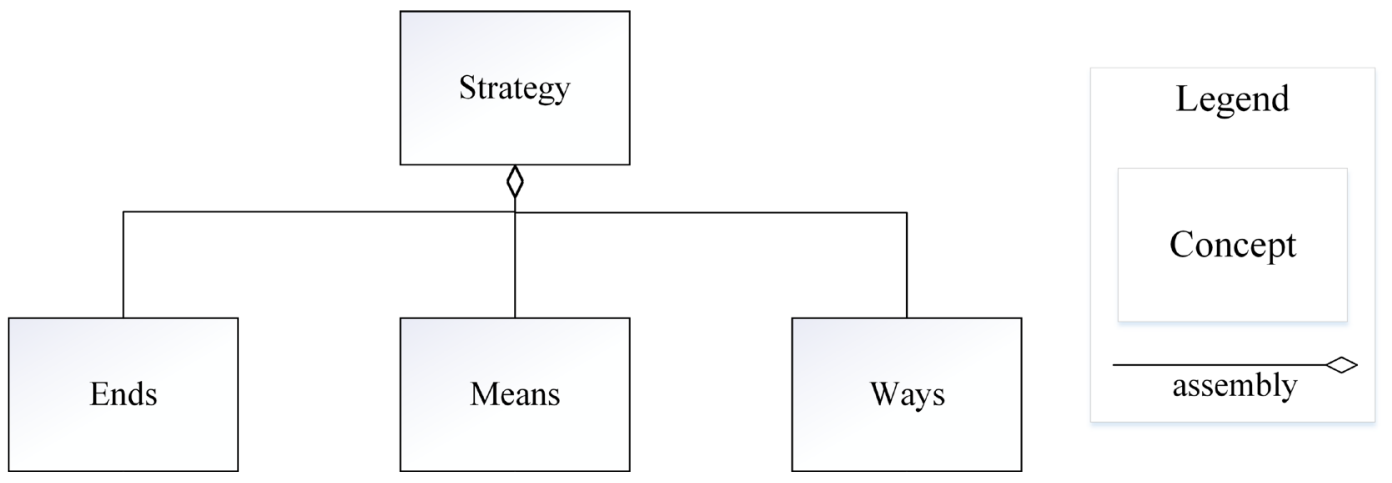

A significant challenge with the work is to align and build consistency between the concepts without applying "mental nudges". The reality creates the difficulty that few authorities define the terms they use, use terms interchangeably, use them in different ways, or when definitions are offered; there are issues with the correspondence between the concepts (Ogden 1923).

\section{Analysis}

As multiple views are required collectively to describe strategy, the authors will take each view in turn to understand its makeup.

The goal is to bring all views together as a single system of reasoning, resolve any conflicts, if necessary, and verify there are no gaps in the enterprise's ability to create the value to achieve the vision. These gaps may be caused by structural misalignment with the value chain (Porter, 1986) or by lack of maturity of required capabilities (Pham et al., 2013) or similar factors. Gaps are experienced as internal pain points within the enterprise (The Open Group, 2018a).

\section{Ends, Means, and Ways}

At its most straightforward, a strategic plan, a strategy has three parts: the end, the means, and the ways (Dorff, 2001). These represent the "core generalisations" of all parts of a strategy.

Ends are the objectives or goals being sought. Means are the resources available to pursue the objectives, and ways or methods are how one organises and applies the resources (Dorff, 2001).

These questions are essential because they must design, deploy, and organise the building blocks of its structure and behaviour suitably for business to achieve the ends. Misalignment between intent and ability creates friction and slippage and the loss of necessary agility to attain the desired end.

Figure 1 shows the critical semantic concepts related to strategy: A strategy is composed of ideas about the ends (i.e., its purpose or aspirations), the means or resources by which these ends will be achieved, and the ways that plan will be carried out to use the means to achieve the ends. Thus, Strategy is an assembly of strategy elements (i.e., ends, means, and ways).

Adding additional components to the model at this stage does not add information, but obscures, for example, within strategy formation, that risk is everywhere. There is risk in the means that are selected and those that are not. There are risks in the aspirational ends that are pursued, and those that are not, there is risk in executing the strategy and risk in pursuing a strategy or having no strategy at all.

This basic view, while incomplete, is a framework (scaffolding) that is the basis of a more complex structure composed of many elements. The scaffold is critical as it guides the general outline and provides anchor points for describing, understanding, maturing. Applying thought about what is necessary and sufficient within strategy for it to be complete and consistent. Therefore, it is for it to 
be unified. While none of these features will, in and of themselves, necessarily produce a successful, or even useful, strategy, they are the preconditions of what is needed.

In the enterprise context, the two most basic approaches to strategy formation can be broadly identified as market-centric, and resource-centric (Barney, 2007) While the nature of the latter can be identified within the concepts and structures of strategy, the nature of market strategies requires an understanding of the levels of planning to identify and engage the market.

\section{Levels of Planning}

It might be thought that it would be instructive to investigate history for insight into planning levels. However, the reality is that distinction in thinking and understanding has evolved since World War II does not exist or is conflated or ignored (Marston \& Leahy, 2016).

\section{Levels of Decision Making in a Military Context}

No universal agreements of the level of decision making in a military context exist. Nevertheless, it is common to classify decisions into the following categories:

1. Grand Strategy: It contains the political ends desired between each of two actors and the means and ways applied to achieve them (von Clausewitz, 2019). Grand strategy is created entirely in the minds of the political leadership (Boyd's mental tapestry) (Boyd, 1987b) and considers the prioritisation and scale of national investment in portfolios of technology.

2. Theatre Strategy: It is guided by grand strategy to describe the military ends desired between each of two actors and the means and ways applied to achieve them (war is a continuation of policy with other means) (Holmes, 2014; von Clausewitz, 2019). Theatre strategy is created entirely in the minds of military leadership.

3. Operational Planning: It translates from the mind to the map actions set out in the strategy. The blueprint determines the tactical engagements that allow achieving the strategy based on infrastructure systems and resources (Rao, 2011).

4. Tactics: They apply fire and manoeuvre/fire and movement and standard and nonstandard battle drills to execute the plans and methods set out within the operational planning through interconnected resources directly engaged with one another. (Place, 2000a). The nature of the terrain and the available technology can be pivotal.

5. Technology: The enabling technology, the plant, infrastructure, and equipment are made available through the prioritisation of investments, driven by the grand strategy's direction (Sinder, 2001).

\section{Levels of Decision Making in an Enterprise Context}

By analogy to the military classification of decision, the following list sets out the categories of decision making within the enterprise:

1. Corporate Strategy: It is primarily concerned with how a business approaches its environment (Mintzberg et al., 2005). It is used to ascertain business lines or plans for, and differentiation across, the value streams and activities (Porter, 1996), business services and their flows (McDavid, 2016), and the adoption of classes of technology by whatever means (Mintzberg, 2007). In this way, the corporate strategy informs its resource strategy.

2. Business Strategy: In multi-division organisations, business strategy converts the direction provided by corporate strategy into internal plans for each business (Mintzberg et al., 2005). In addition, (Jaques, 2003) recognised the inherent size of the problems require each is addressed in a different stratum of the enterprise. 


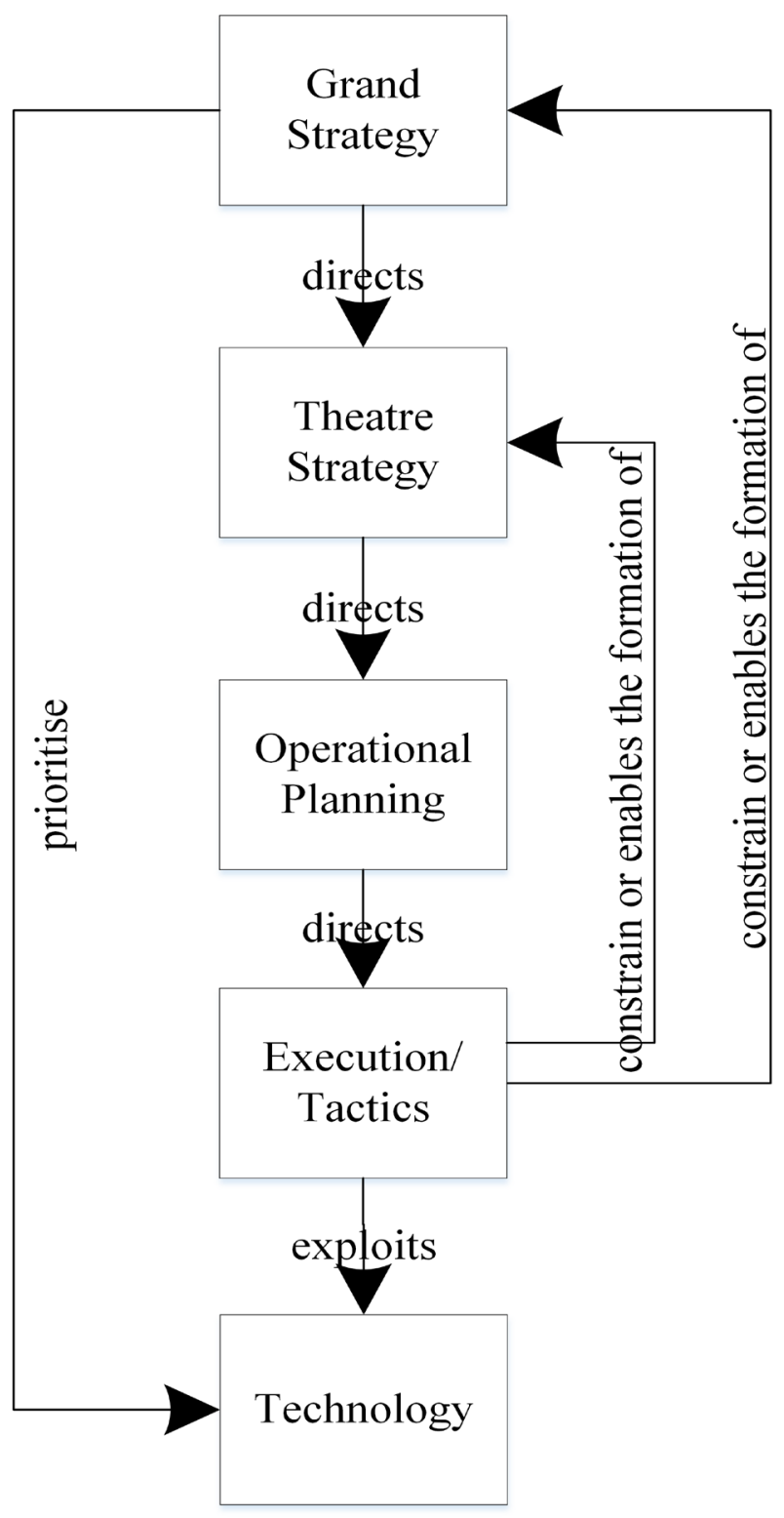

The business strategy focuses on questions of market positioning, what capabilities will be needed, and what approaches will create new opportunities (Lynch et al., 2003).

3. Functional Level Strategy: It involves creative and intuitive decision making of the specified associated clusters of accountabilities within the organisation, (Mintzberg et al., 2005; Ohmae, 1988) within the relevant overarching direction strategy which capabilities must be matured to achieve performance requirements.

4. Operational Planning: It is within the purview of middle management. It is primarily concerned with accurately translating the strategy into a cohesive and actionable implementation plan and 
measuring progress against the plan. It addresses questions on how to create or enhance the capabilities that are needed.

5. Tactics: By analogy with the military equivalent, tactics are the concern of lower management and first-line supervision and address the short-term use of the operational plan's direction.

6. Technology: The plans for enabling technology, the plant, infrastructure, and equipment made available through the prioritisation of investments is expressed in the resource strategies, which are driven by the direction set within the corporate strategy.

In the structural view in Figure 2, the grand strategy informs or directs the theatre strategy, which directs the operational planning, which, in turn, directs the execution/tactics decisions, which exploit the results of the technology decisions. The mix of investment in technology is informed by strategic decisions (Cerami \& Holcomb, 2001), and the tactical capacity and capability, both constrain and enable strategy (Place, 2000b). In each case the subordinate plan is constrained by and must align to its superior, thus ensuring optimisation of the entire system of plans, failure to do so, resulting in suboptimisation (Deming, 2000).

These five levels give military personnel a common framework for establishing a clear and consistent understanding of the context of decision-making challenges and the means to address these challenges within an enterprise.

In the business context, the levels for a precise understanding of the planning will vary by its size. However, a similar framework can help to understand the analogous processes (Mintzberg, 2007).

Thus, a strategy may be a corporate strategy, a business strategy, a functional strategy, or a resource strategy for an enterprise. Each of these strategies informs the other strategies and informs technology investments and is informed by execution. Working within this, or a similar framework, provides business planners with the tools to develop and share a clear and consistent understanding in discussing business objectives and means by which they may be attained.

\section{COMPOSITE}

Ends, means, and ways cannot be adopted in a vacuum. Many things can affect their character, development, or behaviour. The primary influencers that guide the shape of strategy, what the executive think about the primary sources of pressure or change on the enterprise include the following:

- Environmental Forces and Drivers: They are the factors that create risk in change or change in interactions in the state of things that may affect the enterprise (Lindgren \& Bandhold, 2009). These are the forces in the environment that act as a system (Lindgren \& Bandhold, 2009) and include the elements that create Porter's (2008) five forces. They may consist of a wide range of forces, including other drivers that influence the ability to achieve a vision. Environmental forces and drivers are composed of:

- Economic forces, namely trends and changes in the economy's state, the concentration of wealth, industrial diversification, macro and micro globalisation, and attitudes toward growth and competition.

- Political forces, namely the state of, and the trends in, government stability, attitudes to corruption, and government intervention in the economy.

- Social forces shared beliefs, and attitudes of the population, namely availability of skills, attitudes toward the forces and drivers (i.e., birth rates), attitudes to technology, and attitudes toward the environment.

- Technical forces, which means the technological landscape considers changes and how they impact the way businesses market their products (e.g., the impact of the Internet, artificial 


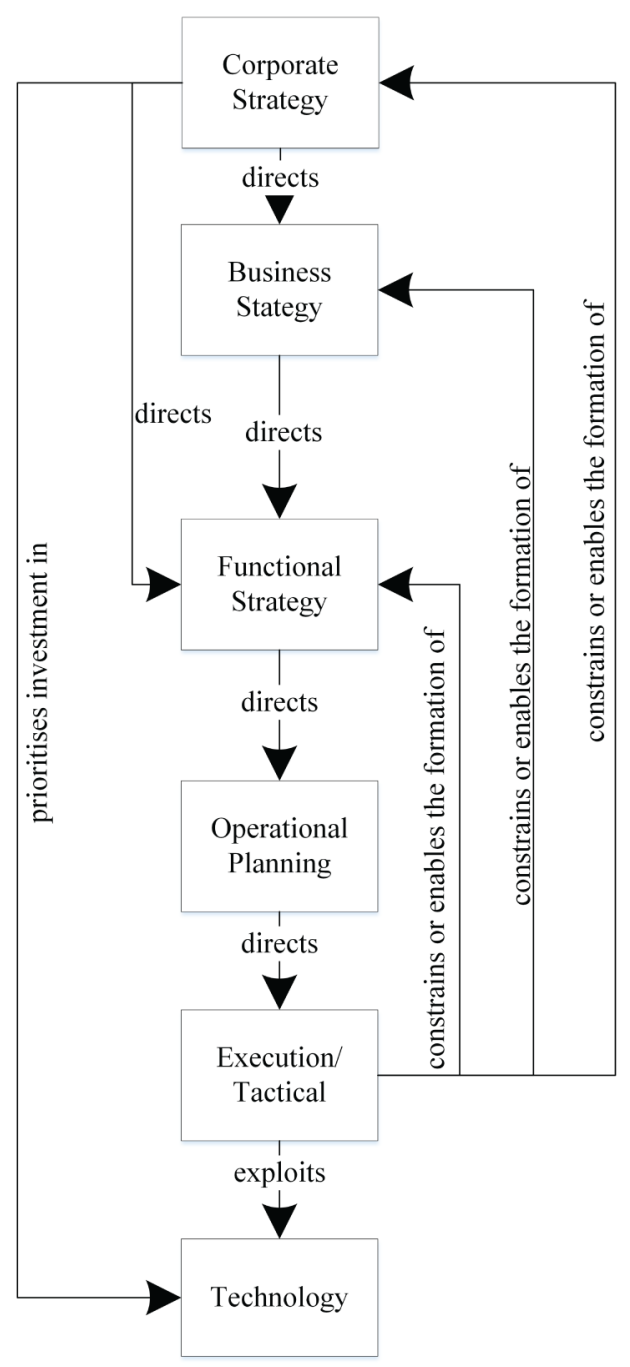

intelligence (AI), and mobile technology), changes in the maturation of technology (Wardley, 2018), and the concentration of technology within an industry.

- Natural forces, namely trends in the climate, weather, and other parts of the physical world.

- Legal trends, namely the broad state and direction of the laws of the land.

- Market and industry changes within an industry or sector of the economy lead to competition changes in the macro-environment.

Within the environmental forces and drivers, the strategy, and therefore the enterprise will find, within the trends and interplay of the environment variables, the basis for differentiation, and perhaps existential threats.

- Organisational Culture: It is the weighted portfolio of values of the business (Heskett, 2011). Culture may often be the principles that an organisation adopts to make its unique social and psychological environment explicit (Boyd, 1986). 
In “The New Economics for Industry, Government, Education', Deming argued that culture is the underpinning force for creating transformational strategy (Deming, 2002).

- Constraints: They are the external factors that prevent or dictate an organisation's pursuit of an approach to meet the end to which it aspires. These are expressed in the relationships in a structured form.

In determining its means, an enterprise must understand what structural and behaviour building blocks it has at its disposal while simultaneously developing an appreciation for any current gaps in its ability to execute its strategy and achieve the desired end.

\section{INTERACTION AND INTERPLAY}

Strategy is about change. For this reason, wholly static views do not tell the entire story to recognise its components. While Figure 4 is useful, it does not identify the interactions and interplay between the concepts of which strategy and strategic planning are composed. As a complex system, the dynamic view of strategy exposes circular, interlocking, frequently time-delayed relationships among its components, a fact that is just as crucial in understanding its properties as understanding the individual components themselves.

In this view, also, the basis for resource-centric strategies is evident. When an organisation has the right bundles of resources (i.e., means) relative to its competition, these can become the basis of a resource-centric strategy. The leverage of these resources can act as the fulcrum.

A dynamic view of the components of strategy in a system creates an authoritative answer to the question "which comes first, strategy or architecture?" (Parker \& Brooks, 2008). Figure 5 applies the fundamental concepts of Figure 4 into a behaviour model. Whereas Figure 4 shows the structural relationships been the strategy elements, Figure 5 then shows these same concepts in dynamic relationships, each numbered to facilitate linking them to the items in the following list.

Pressures may negatively or positively impact other pressures. In other words, culture constrains, strategy (Stein, 1985, Deming, 2000) and may itself be changed by executing a strategy (ISO, 2018). This means that changes in the level, nature or interaction of pressures will require changes in strategy, with implications for decision-making:

1. Pressure may negatively or positively impact (what) end (may be pursued) (Boyd, 1992).

2. Pressure may negatively or positively impact (the viable) way(s) (employed within the strategy) (Boyd, 1992).

3. Pressure may negatively or positively impact (the) means (available) (Boyd, 1992).

4. The ability to carry out a course of action (action plan) may negatively or positively impact (what) end (may be pursued) (Boyd, 1992).

5. Courses of action may negatively or positively impact (the) pressure (that influences strategy) (Boyd, 1992).

6. Ways (courses of action) may create or eliminate a gap (Boyd, 1992).

7. Gaps may negatively or positively impact the means (available for strategy execution) (Boyd, 1992).

8. Gaps may negatively or positively impact (how a) pressure (influences the strategy) (Place, 2000b).

9. Means may negatively or positively impact (how a) pressure (influences the strategy) (Boyd, 1992).

10. Ways may negatively or positively impact (how a) pressure (influences the strategy) (Boyd, 1992). 


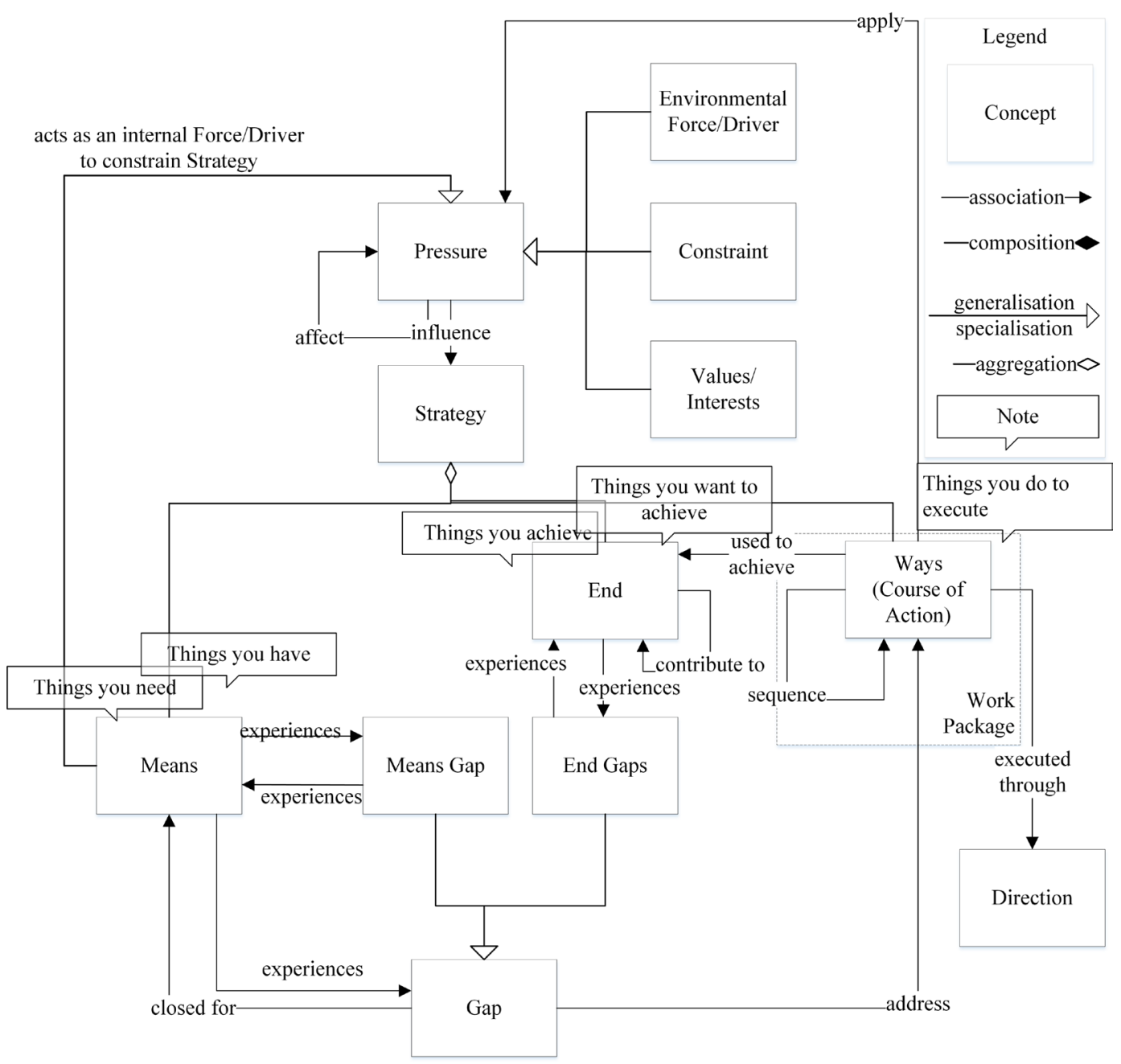

11. Pressures may negatively or positively impact how (that is followed or applied) (Boyd, 1992).

12. Ways (courses of action) may be executed through direction provides to subsidiary plans, i.e. The business strategy is a subordinate plan to the corporate strategy.

This view is essential because it shows that changes in ends (vision or aspirations), while achieved through the ways the enterprise employs, are constrained by the available means and the ability to address the gaps between available means and needed means.

Because they provide the basis for coherent action, indeed, strategy without a sound architecture is "the noise before defeat," to paraphrase Sun Tzu (c 500) the gaps between the "as-is" architecture of the enterprise and its "to be" or strategically desired structure and behaviour are essential to strategy, Further, implementing strategy without understanding the gaps within the enterprise's current structural and behavioural means (which are established through the identification of its architecture) leads to chaos and waste as the organisation tries to move forward.

In the long-term, the nature of the pressure changes through the ways they successfully change or change the enterprise's relationship concerning its environmental forces/drivers, values/interests, 


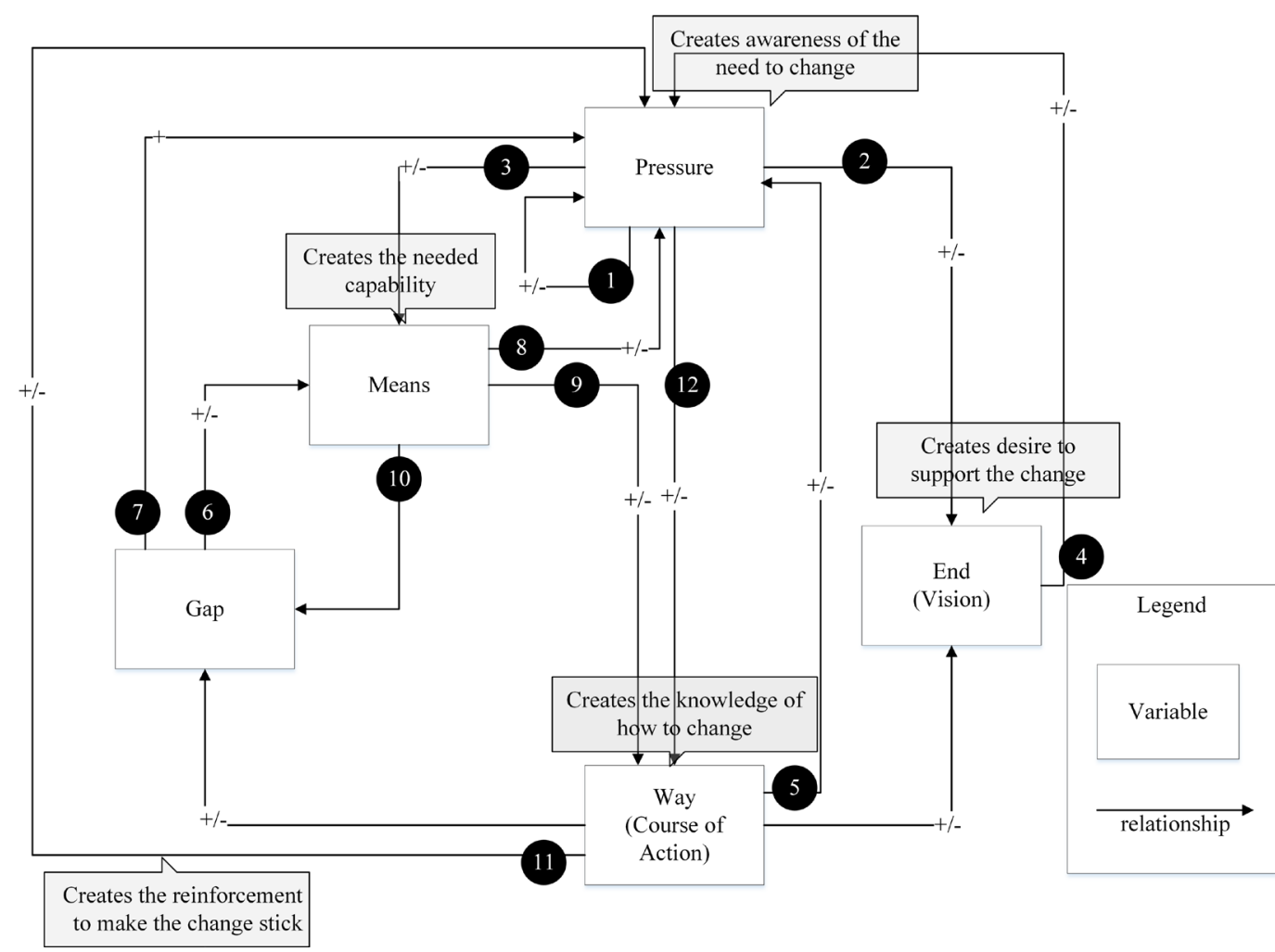

and constraints. These may result in tipping points being crossed and the nature of a variable or the relations may change from positive to negative or vice versa. For example, a culture can be changed from low trust to high trust; this introduces new pressures that will influence the strategy in entirely new ways. In other words, the context of a strategy and the strategy itself will be subject to continuous pressures and consequent evolution and are based on assumptions that must be challenged during strategy formation.

As a result, it is essential not just to understand the structural relationships between the parts of strategy but also their behavioural or dynamic nature (Sterman, 2000).

\section{Risk}

As a strategy unfolds, it will create, exploit, or change the associated risks or uncertainties. Each of the elements making up strategy (i.e., the strategy elements within its ends, means, and ways) may either generate or address, and therefore reduce risk. Indeed, the very essence of strategy is to balance risk in the pursuit of the strategic return (Porter, 1996).

In the short term, risks may act as constraints or threats to success, as items to be controlled or treated (ISO, 2018), and must be factored in assessing whether the end set out in the strategy is worth the investment and effort.

In the longer term, while certain risks may be eliminated, others may continue, and new risks may come into play, touching elements of strategy in new ways. Because of these realities, the active management of risk is based on a clear understanding of the uncertainty associated with each element of a strategy (ISO, 2018).

Table 1shows the concepts related to risk, which Figure 6 illustrates subsequently. 
Table 1. Concepts related to risk

\begin{tabular}{|l|l|}
\hline \multicolumn{1}{|c|}{ Label } & \multicolumn{1}{c|}{ Concept } \\
\hline Assumption & Something which is taken to be true (Simpson \& Weiner, 1989). \\
\hline Control & $\begin{array}{l}\text { The actual countermeasures or other mechanisms that a business organisation puts in } \\
\text { place to manage the risks it takes. } \\
\text { Controls may include existing policies, devices, procedures, and practices (ISO, } \\
\text { 2018). }\end{array}$ \\
\hline End & The objectives or goals sought (Dorff, 2001). \\
\hline Risk & $\begin{array}{l}\text { The effect of uncertainty on objectives (ISO, 2018). As the enterprise's objective is to } \\
\text { create value, this is interpreted as the "effect on the value." }\end{array}$ \\
\hline Risk Owner & A role is answerable for the status of the risk (ISO, 2018). \\
\hline Strategy Element & $\begin{array}{l}\text { A generalisation representing any atomic structural or behavioural component of the } \\
\text { enterprise (any part of the end, means or ways). }\end{array}$ \\
\hline Strategy Element Owner & The role is liable for the performance of the strategy element. \\
\hline
\end{tabular}

The propositions concerning risk in the context of a strategy are:

- An assumption is held about a risk (ISO, 2018).

- A risk may impact another risk (ISO, 2018).

- Control is exerted over a risk (ISO, 2018).

- Risk effects (the ability to achieve a valued) end (ISO, 2018).

- A risk owner is liable for a risk (ISO, 2018).

- A strategy element generates the need for or creates or addresses a risk (ISO, 2018).

- A strategy element owner is liable for a strategy element (each of the ends, means, and ways within the strategy).

- A strategy element may have relationships with other strategy elements (Mintzberg et al., 2005).

From a practical perspective, a strategy may have risks that exist because of any of the following conditions:

- A risk may exist due to a gap (i.e., a missing or underperforming component) within the current or future business design.

- $\quad$ Risk may occur because the vision (end) is not appropriate.

- Risk may occur if the flow or alignment between components is incorrect.

- Some risks do not change (i.e., do not have a way), change too slowly, and change too fast.

It is not a risk if a component is overperforming; it is an issue because it costs too much about the value it creates.

Beyond risks in the strategy and its plan, some risks also arise within strategy execution; they are project and transformation risks and therefore not unique to or part of strategy itself.

In the dynamic context, risk again is ubiquitous; risks may either positively or negatively act on or be acted on by any strategy elements.

\section{Alignment/Integration}

In a business context, the end is not an atomic or singular concept, but a complex idea that includes insight into the value proposition. Specifically, the end includes the nature of the service being 

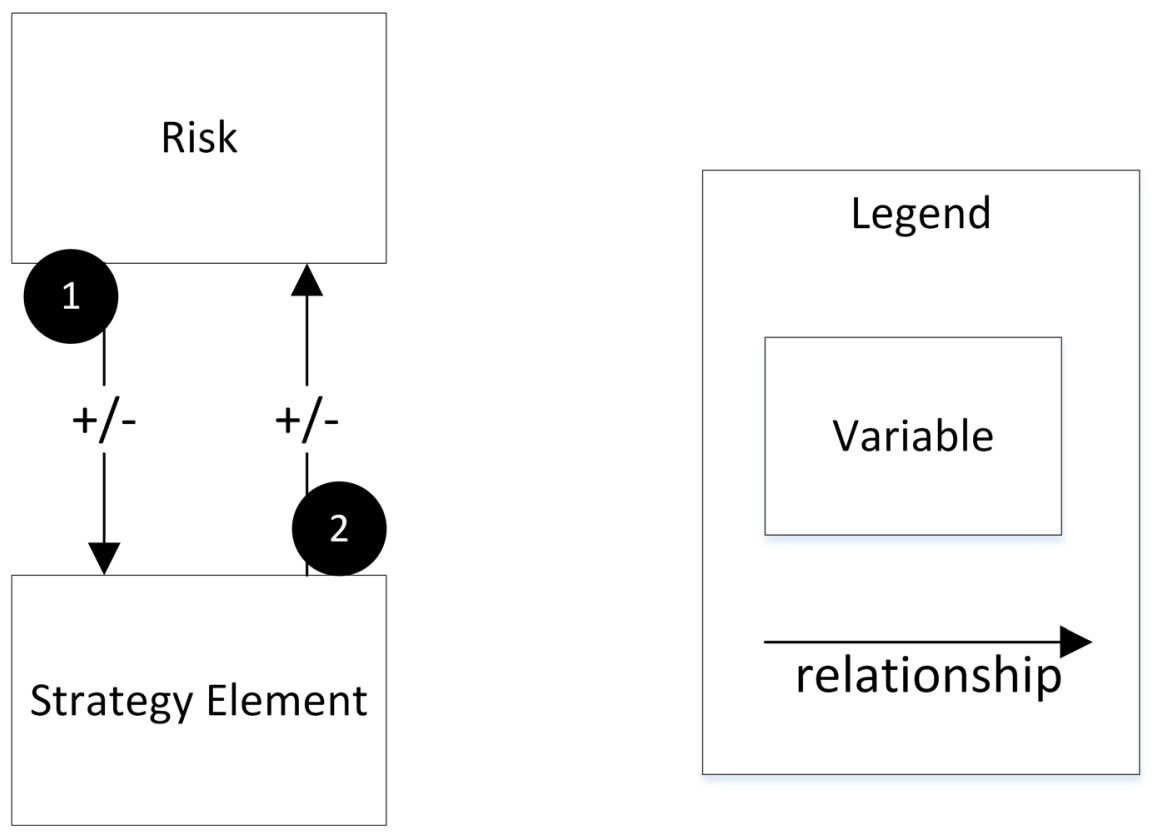

delivered, to whom it is delivered, what is motivating the beneficiaries' interest in the value, and strictly what value is being provided.

Figure 8 illustrates a service that is accountable for creating value and the beneficiary's recognised needs (McDavid, 2016). These needs are modified by the beneficiary's desires, representing their requirements or quality measures (Collis, 2008) and the beneficiary experiences as pain points (The Open Group, 2018a).

In developing a strategy, the business must choose which desires or quality measures to use as the basis for competition. Failure to chose, make the necessary trade-offs, and align strategy elements will result in a poorly formed strategy (Porter, 2008). Indeed, all the instances of all the elements for all the concepts and relationships must be in cohesive harmony and achieved by a synthetic decisionmaking process, rather than by analysis (Boyd, 1992).

\section{Value and Differentiation}

According to Porter (1996), "strategic competition can be thought of as the process of perceiving (and taking) new positions to woo customers from established positions or draw new customers into the market" (p.65). In Porter's view, strategy and strategy formation is distinct from the state of best practice seen within differences in ... effectiveness. The ability to draw new customers is achieved primarily by creating differentiating value in customers' eyes (Collis, 2008). This is called "market positioning." In the case of value differentiation and market positioning, the strategy components are presented in Figure 9.

Table 2 presents the concepts that contribute to the specification of value and differentiation within the enterprise's positioning in a competitive situation.

1. A line of business (within an enterprise) provides one or more business services (Hamel \& Prahalad, 1996).

2. A business service creates value (Open Group, 2017) in the form of an outcome (ISACA, 2019).

3. A beneficiary is classified and identified by its circumstances (Kotler \& Armstrong, 2012). 
Figure 7. Dynamic view of the critical strategy elements and risk
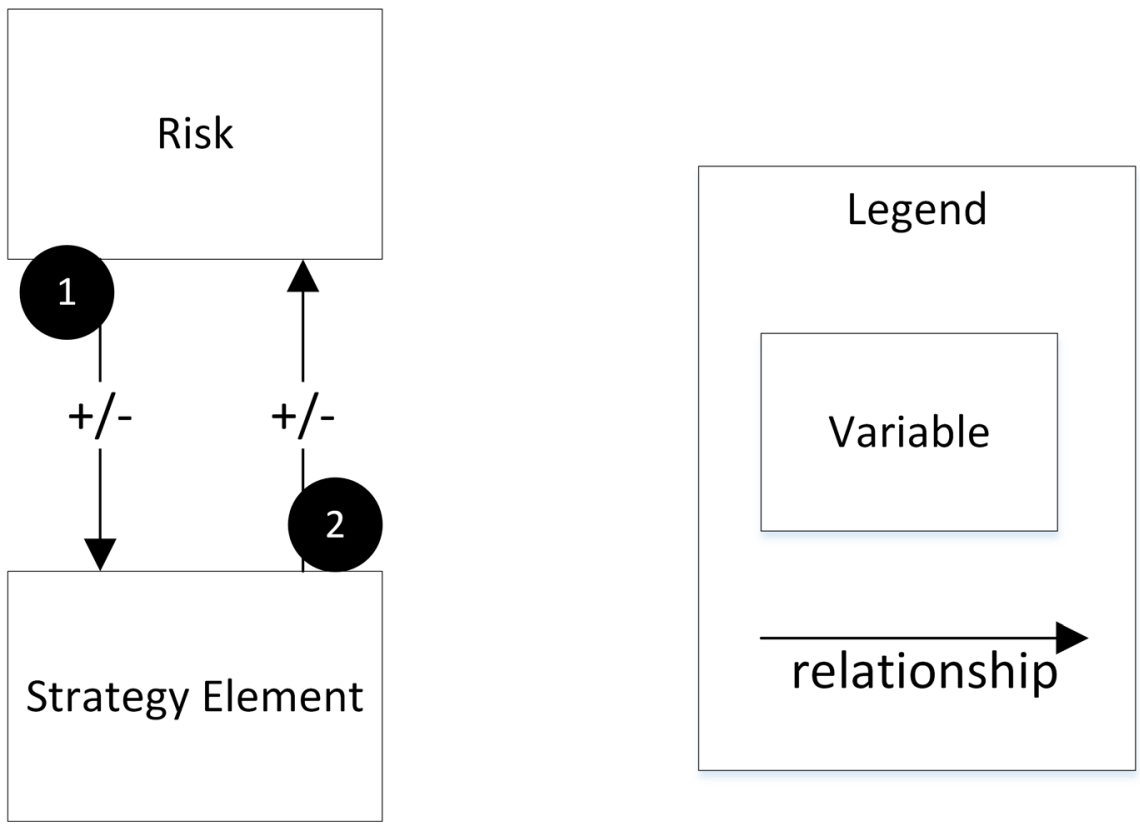

Figure 8. Alignment of critical components of the strategy

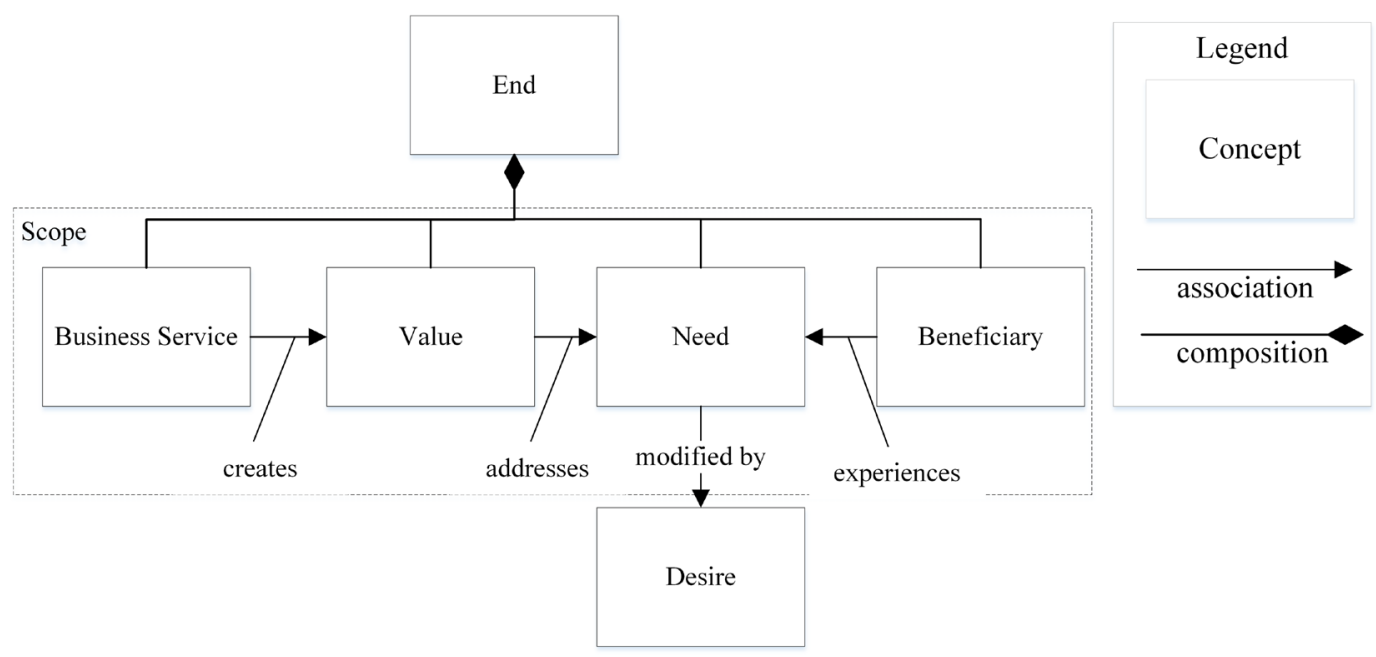


Figure 9. Alignment of key components and relations of benefits and differentiation

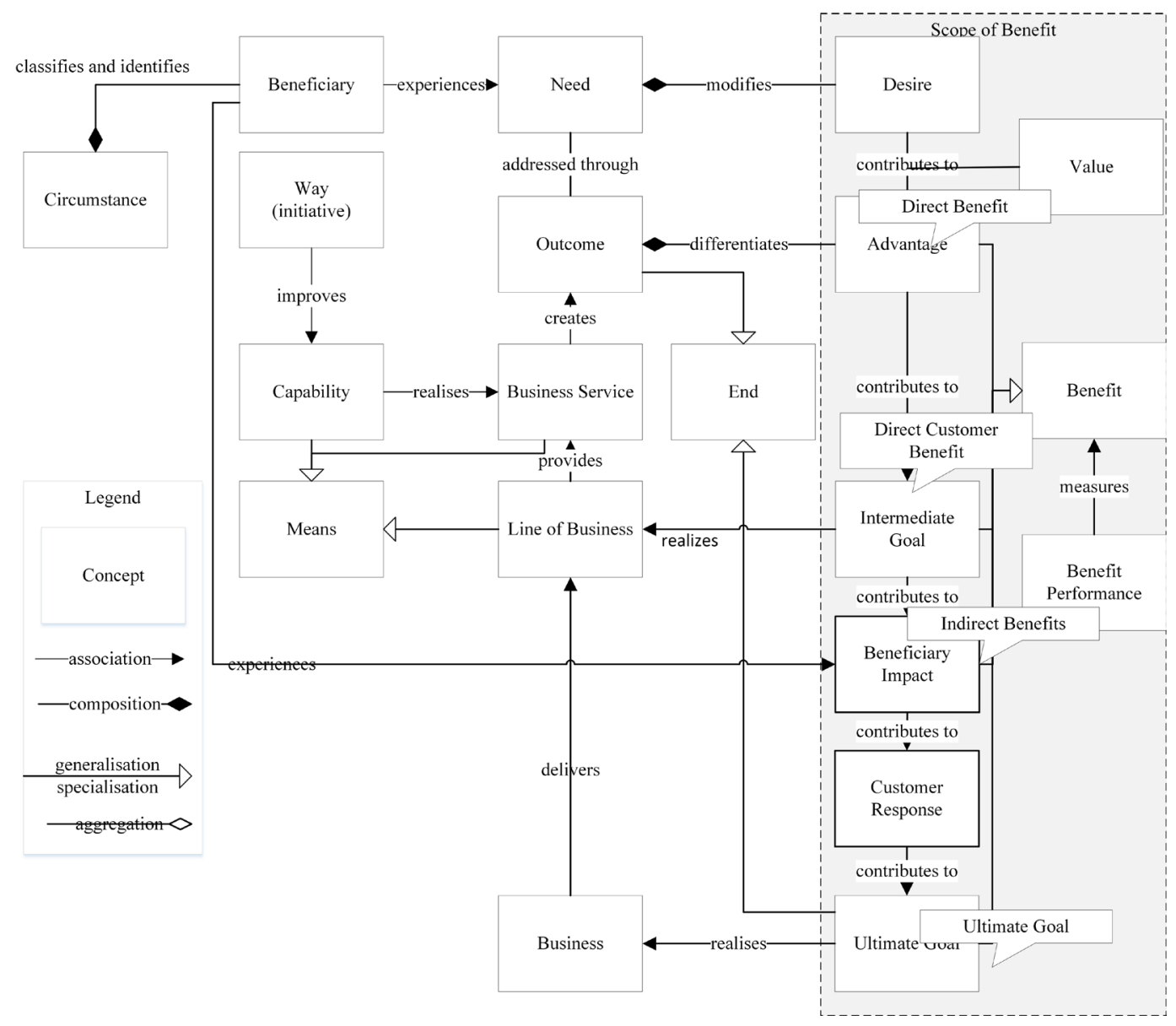


Table 2. Concepts

\begin{tabular}{|c|c|}
\hline Label & Concept \\
\hline Advantage & $\begin{array}{l}\text { A characteristic of service delivery that makes the enterprise distinctive (Collis, 2008). } \\
\text { Statements that indicate what is critical or essential in the business strategy. An advantage or } \\
\text { profit gained from the features within the business services' output (Collis, 2008). }\end{array}$ \\
\hline Beneficiary & $\begin{array}{l}\text { For whom do we do it? (Beneficiaries may be individuals or institutions.). } \\
\text { Beneficiaries may be customers of the enterprise (Collis, 2008) or those seeking pecuniary gain } \\
\text { (owners) (Veblen, 1904). }\end{array}$ \\
\hline Beneficiary Impact & The direct change to the intermediate goal. \\
\hline Benefit & A requirement sought by the customer (Kotler \& Armstrong, 2012). \\
\hline Benefit Performance & A quantitative or qualitative measure of a benefit. \\
\hline Business & A legal entity offering value to its customers (Simpson \& Weiner, 1989). \\
\hline Business Service & $\begin{array}{l}\text { While acting as an encapsulation of a set of activities and resources (and without exposing the } \\
\text { details of how such resources are produced), a business service is accountable for producing a } \\
\text { valued output and therefore for what value is created (The Open Group, 2018a). }\end{array}$ \\
\hline Capability & $\begin{array}{l}\text { The ability to combine parts of the enterprise to create the desired effect reliably and } \\
\text { consistently under specified conditions (The Open Group, 2018a). }\end{array}$ \\
\hline Circumstance & $\begin{array}{l}\text { It identifies the nature of the distinctions of those with a need recognised by the enterprise and } \\
\text { therefore, may benefit. }\end{array}$ \\
\hline Desire & $\begin{array}{l}\text { The feelings, experiences, features, wants, and interests that consumers aim to have or to } \\
\text { achieve to feel better. Desires can, therefore, be a source of advantage for the business that is } \\
\text { best equipped to most closely fulfil them by addressing gaps within current substitute options } \\
\text { (also known as requirements, quality measures or the "voice of the customer") (Kotler \& } \\
\text { Armstrong, 2012). }\end{array}$ \\
\hline End (Mission) & $\begin{array}{l}\text { The objectives or goals sought (Dorff, 2001). } \\
\text { As the business's purpose is to create values, the "objectives" or "goals" must be described in } \\
\text { terms of value delivered. }\end{array}$ \\
\hline End (Vision) & An overall image of what the organisation wants to be or become (OMG, 2015). \\
\hline Intermediate Goal & The indirect benefits of the program or line of business that accrue from the direct benefits. \\
\hline Line of Business & $\begin{array}{l}\text { Also, business unit. A logical view of the hierarchy of accountability to cover all the functions } \\
\text { that carry out a policy or course of action (Jaques, 2003). }\end{array}$ \\
\hline Means & The resources available to pursue the objectives (Dorff, 2001). \\
\hline Need & Something required because it is essential or imperative (Simpson \& Weiner, 1989). \\
\hline Outcome & $\begin{array}{l}\text { The effect of the change in the level of need achieved by the output in pursuit of the } \\
\text { organisational strategy in terms of the result's value. }\end{array}$ \\
\hline Ultimate Goal & $\begin{array}{l}\text { A high-level statement of intent, direction or desired end state for an organisation and its } \\
\text { stakeholders (Collis, 2008). }\end{array}$ \\
\hline Value & $\begin{array}{l}\text { The effect achieved by the output on the wants or desired benefits in the market (Kotler \& } \\
\text { Armstrong, 2012). }\end{array}$ \\
\hline Value Differentiator & The differentiation in the provision of value to a customer (Collis, 2008). \\
\hline Way (initiative) & Methods of how resources are organised and applied (Dorff, 2001). \\
\hline
\end{tabular}


4. Beneficiaries experience needs (that are recognised by the enterprise) (Kotler \& Armstrong, 2012).

5. The extent to which a need is addressed is modified by (the feeling of) value (Kotler \& Armstrong, 2012).

6. Outcomes are differentiated by advantage (Collis, 2008).

7. The alignment of advantage to desire creates an advantage (Collis 2008).

8. Means are a generalisation of capability, business service, and line of business.

9. A way (initiative) improves capability (Boyd, 1992).

10. Benefits are a generalisation of advantage, immediate goal, beneficiary impact, and ultimate impact.

11. An advantage contributes to an immediate goal.

12. An immediate goal contributes to the beneficiary impact.

13. The beneficiary impact contributes to the ultimate impact.

14. The business realises the ultimate impact.

As strategy rests on unique activities (Porter, 1996) (i.e., answers the question, what can then be used to determine what the actions are that needed for the enterprise to be unique), Collis (2008) identified the customer's desires, or quality measures, as the source of strategy.

Within the benefit chain, an example may be helpful. Imagine a business service provides and therefore addresses the need for food for some segment of beneficiaries. Assume also that members of this market segment desire their food to be low price. A business that can continuously offer low price as a key part of the advantages it offers will achieve an immediate goal of gaining customers, which will contribute to the intermediate goal of the business of attracting customers, which, in turn, will impact on the beneficiaries by building loyalty within their ranks. This will then potentially lead to the ultimate goal of, for example, expanding the market share of the business, whereby it achieves its strategic end. In this way, the differentiation's value based on low-cost leads to the market position's value.

\section{TIME AND RESOURCES}

Arguably, the most important component of strategy is left for last. The set of components capturing the time phasing of execution is exposed through the decision loop (Boyd, 1987b). Both time and decisions are concepts. While time is abstract, it can be named and counted, and decisions themselves can be counted; therefore, the role and nature of both must be recognised and accounted for in all strategy. Indeed, Boyd (1976b) argued that "he who can handle the quickest rate of change survives" (p.24).

This decision loop contains four stages. Its crucial measure is the speed with which the loop can be repeatedly executed, as the end, means, and ways are all evaluated as unfolding circumstances. In business terms, this refers to the manoeuvrability of the enterprise, and it may refer to the fact that many writers believe that strategy is emergent (Mintzberg et al., 2005).

The decision loop begins with unfolding the current ends, means, and ways of the business and those in its "battlespace" (competitive market). These conditions are then studied (observe). Then, the observer (in this case the enterprise) determines what these conditions mean and what is to be done and not done in response to these conditions (Vermeulen, 2017) (typically through a strategy document that contains and explains the strategy). Based on this (orient), a strategic plan for the enterprise may be formulated and approved (decide). The strategic plan details the plans to achieve that strategy. It documents and communicates how the strategic plans will be implemented and then carried out (act) before the cycle is repeated.

Finally, it should be observed that this loop exists and provides feedback between each of the decision layers. Hence, integration of the relationship between each component of the decision cycle is essential for all aspects of strategy, for strategy formation, implementation, and execution. Boyd 


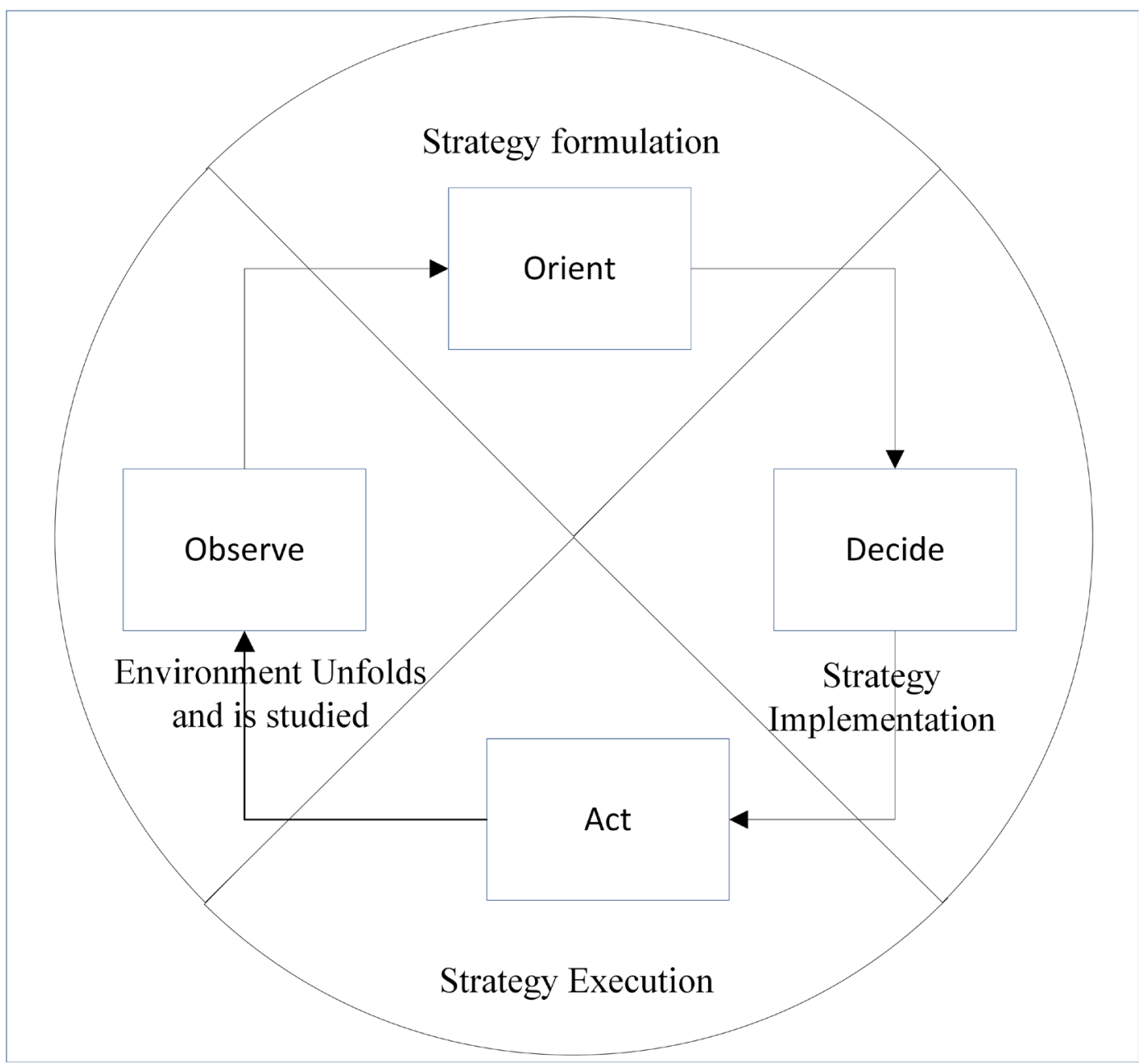

saw the observe-orient-decide-act loop at every level of the military decision-making process: Grand strategy, strategy, grand tactics, and tactics. Further, Martin (1995) observed that, in a knowledgecentric world, the strategy cycle must create circumstances that challenge everyone to the maximum without there being a burdensome and paper-centric (control-based) process.

\section{SYNTHESIS}

Each of the concepts and relationships within each of the preceding viewpoints, either explicitly or by connection, links to a core generalisation (i.e., end, way, and means). The result is that the sum of these components and relationships identifies the requisite parts of strategy.

Thus, strategy formulation may, through synthesis, resolve conflicts and optimise choices in these orthogonal views to synthesise a final product whereby all aspects are addressed a single plan of action. This balance requires finding out how to achieve the ends and adjusting ends to find those realistic ways to meet them by available means (Freedman, 1985). 


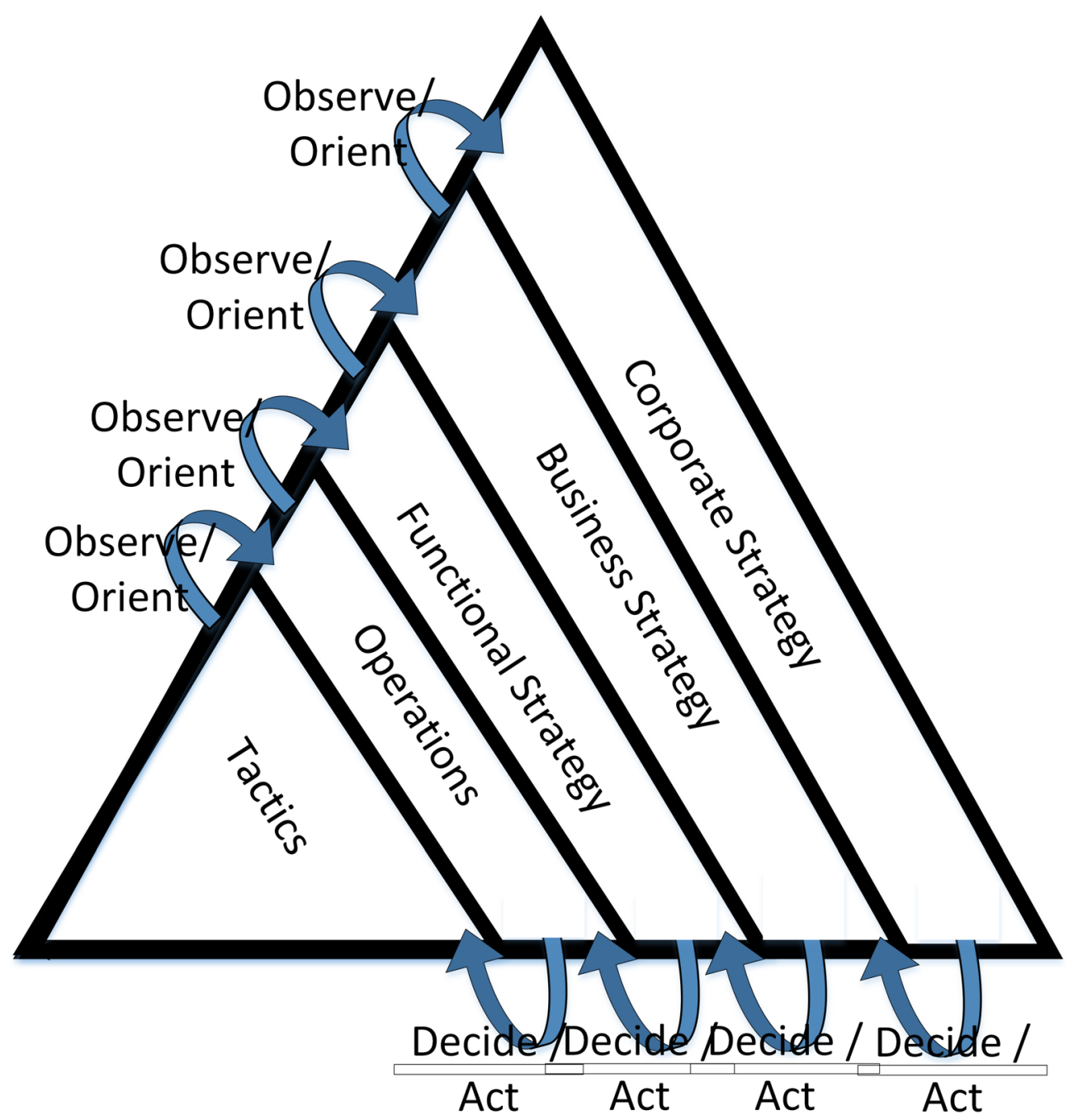

Further, any gap between what is needed in terms of ends or exists in terms of means is experienced as a "pain-point" (Simpson \& Weiner, 1989) requiring action to improve its ability to execute the intended strategy.

\section{CONCLUSION}

A critical insight from this analysis is that a strategic plan that is not a requisite is, therefore, by definition, not a strategy. However, by applying the insight into the concepts and relations of strategy in an enterprise context, a complete strategic plan can be developed. It is also clear from the analysis that, while strategy formation must have a clear-eyed grasp, the external conditions act on an enterprise. One of the keys to developing a complete strategy is having a shared understanding of all the components and relationships within the enterprise needed to execute the strategy. Identifying and describing current gaps or projecting the future, intentional or "to be," gaps in the enterprise's design promptly become critical factors in the ability to form a sound and successfully executable strategy. 
The use of conceptual and systems dynamics models brings clarity to understanding the specification of that makes up a strategy across its multiple dimensions is understood and the nature of the strategic plan is better understood.

By employing the decision hierarchy that makes and applies to enterprise planning therefore the interactions between the decomposed parts of the strategy, clarity about how value and differentiation are found and described is created, as well as the role of risk, and the how the impact of time needs to be captured within the strategy.

The specification of the concepts involved in strategy formation allows us to explore the patterns of strategy formation easily. Thus, accessing these patterns becomes a further method to accelerate sound strategies and increase confidence in the final product of strategic planning. The result is a greater confidence in the complete specification of a strategy, whereby the components are correctly connected. It also means that, when developing a strategy. The writer can focus on content rather than the structure or features.

Areas of future work include validating the existing industry practices using case studies, connecting planning and execution more clearly, and exploring how strategy is enabled or constrained by the existing structural, and behaviour elements of the enterprise (including culture). 


\section{REFERENCES}

Arp, R., Smith, B., \& Spear, A. D. (2015). Building Ontologies with Basic Formal Ontology. MIT Press. doi:10.7551/mitpress/9780262527811.001.0001

Ashcroft, H. (1965). Corporate Strategy. McGraw-Hill.

Barney, J. B., \& Clark. (2007). Resource-Based Theory: Creating and Sustaining Competitive. Oxford.

Boyd, J. (1976a). Destruction and Creation. U.S. Army Command and General Staff College.

Boyd, J. R. (1976b). The New Conception for Air-to-Air Combat [Unpublished briefing slides]. Organic Design for Command and Control.

Boyd, J. R. (1986). Patterns of Conflict [Unpublished briefing slides]. Boyd's Work — John Boyd Homepage.

Boyd, J. R. (1987a). Organic Design for Command and Control [Unpublished briefing slides]. Boyd's Work — John Boyd Homepage.

Boyd, J. R. (1987b). Strategic game of ? and ? [Unpublished briefing slides]. Boyd's Work — John Boyd Homepage.

Boyd, J. R. (1992). Conceptual Spiral (version dated Jul/Aug 1992). https://static1.squarespace.com/ static/58a3add7e3df28d9fbff4501/t/58a4a5b0a5790ad178d5e09b/1487185329595/Conceptual+Spiral_JulAug+1992.pdf

Brown, S. L., \& Eisenhardt, K. M. (1998). Competing on the Edge: Strategy as Structured Chaos. Harvard Business School Press.

Carroll, L. (2015). Alice's Adventures in Wonderland and Through the Looking Glass. DigiReads.com Publishing.

Cerami, J. R., \& Holcomb, J. F. Jr., (Eds.). (2001). U.S. Army War College Guide to strategy. U.S. Army War College, Strategic Studies Institute. doi:10.21236/ADA392553

Collis, D. (2008). Can You Say What Your Strategy Is? Harvard Business Review, 86(4). PMID:18435009

Deming, W. E. (2000). The New Economics for Industry, Government, Education. MIT Press.

Dorff, R. H. (2001). A Primer in Strategy Development. In J. R. Cerami \& J. F. Holcomb (Eds.), U.S. Army War College Guide to strategy (pp. 10-41). U.S. Army War College, Strategic Studies Institute.

Finkelstein, G. (1989). An Introduction to Information Engineering: From Strategic Planning to Information Systems. Addison-Wesley.

Freedman, L. (1985). Strategy: A history. Oxford University Press.

Hamel, G., \& Prahalad, C. (1996). Competing for the Future. Harvard Business School Press.

Hammond, G. (2004). The mind of war: John Boyd and American security. Smithsonian Books.

Heskett, J. (2011). The Culture Cycle: How to Shape the Unseen Force that Transforms Performance (1st ed.). Pearson FT Press.

Holmes, J. (2014, November 12). Everything You Know About Clausewitz is Wrong. The Diplomat. https:// thediplomat.com/2014/11/everything-you-know-about-clausewitz-is-wrong/

International Organization for Standardization. (2018). ISO 31000:2018 Risk management - Guidelines. https:// www.iso.org/obp/ui/\#iso:std:iso:31000:ed-2:v1:en

ISACA. (2019). COBIT. https://www.isaca.org/resources/cobit

Jaques, E. (2003). Requisite Organisation. Carson Hall and Co.

Jomini, A. (1854). Summary of the Art of War: Or a New Analytical Compend of the Principle Combinations of Strategy, of Grand Tactics, and Military Policy. Greenwood Press.

Kim, W. C., \& Mauborgne, R. (2005). Blue Ocean Strategy. Harvard University Press. 
Kotler, P. T., \& Armstrong, G. (2012). Principles of Marketing (14th ed.). Prentice-Hall.

Lindgren, M., \& Bandhold, H. (2009). Scenario Planning: The Link between Future and Strategy. Palgrave Macmillan.

Luttwak, E. (2002). Strategy: The Logic of War and Peace. The Belknap Press of Harvard University Press. doi:10.2307/j.ctv1c7zfsc

Lynch, R., Diezemann, J., \& Dowling, J. (2003). The Capable Company. Wiley.

Machiavelli, N. (1513). The Prince. Dover Thrift Edition.

Marston, D., \& Leahy, T. (Eds.). (2016). War, Strategy, and History: Essays in Honour of Professor Robert O'Neill. ANU Press. doi:10.22459/WSH.05.2016

Martin, J. (1995). The Great Transition: Using the Seven Disciplines of Enterprise Engineering to Align People, Technology, and Strategy. AMACOM.

McDavid, D. (2016). All Services, All the Time: How Business Services Serve Tour Business. Business Expert Press.

Mintzberg, H. (2007). Tracking strategy: Toward a general theory. Oxford University Press.

Mintzberg, H., Ahlstbane, B., \& Lampel, J. (2005). Strategy safari: A guided tour through the wilds of strategic management. Free Press.

Object Management Group. (2015). Business Motivation Model. https://www.omg.org/spec/BMM/About-BMM/

Ogden, C. K., \& Richards, I. A. (1923). The Meaning of Meaning: A Study of the Influence of Language upon Thought and of the Science of Symbolism. Kegan Paul, Trench, Turner \& Co, Ltd. https://archive.org/details/ in.ernet.dli.2015.221615

Ohmae, K. (1988). The Mind of the Strategist. McGraw Hill.

Parker, T., \& Brooks, T. (2008). Which Comes First Strategy or Architecture? Journal of Enterprise Architecture, 4(4), 47.

Pham, T., Pham, D. K., \& Pham, A. (2013). From Business Strategy to Information Technology Roadmap: A practical guide for executives and board members. CRC Press. doi:10.1201/b14861

Place, T. H. (2000a). Lionel Wigram, Battle drill, and the British Army in the Second World War. War in History, 7(4), 442-446. doi:10.1177/096834450000700403

Place, T. H. (2000b). Military Training in the British Army, 1940-1944: From Dunkirk to D-Day. Routledge.

Porter, M. E. (1979). How Competitive Forces Shape Strategy. Harvard Business Review, 57(2), $137-147$. PMID: 18271320

Porter, M. E. (1986). Competitive Strategy. Harvard Business School Press.

Porter, M. E. (1993). Strategy: Pure and simple. McGraw-Hill.

Porter, M. E. (1996, November-December). What is Strategy? Harvard Business Review, 74(6), 61-78. PMID:10158475

Porter, M. E. (2008). The Five Competitive Forces that Shape Strategy. Harvard Business Review, (January February), 24-40. PMID:18271320

Ralston, B., \& Wilson, I. (2006). The Scenario Planning Handbook: Developing Strategies in Uncertain Times. Thompson.

Rao, V. (2011). Tempo: Timing, Tactics, and Strategy in Narrative-Driven Decision Making. Ribbonfarm.

Schein, E. H. (1985). Organizational Culture and Leadership. John Wiley \& Sons.

Simpson, J. A., \& Weiner, E. S. C. (Eds.). (1989). The Oxford English Dictionary (2nd ed.). Oxford University Press/Clarendon Press. 
Spewak, S. H. (1992). Enterprise Architecture Planning. Wiley-QED.

Sun Tzu. (c 500 BCE). On the Art of War. www.literaturproject.com/art-of-war

The Open Group. (2018a). ArchiMate 3.1 Standard. https://pubs.opengroup.org/architecture/archimate3-doc/

The Open Group. (2018b). The Open Group architecture framework (version 9.2). Author.

U.S. Joint Chiefs of Staff. (1964). Department of Defence Dictionary of Military and Associated Terms 8 November 2010 (as Amended Through 15 November 2013). Director for Joint Force Development.

Veblen, T. (1904). The Theory of Business Enterprise. Charles Scribner \& Sons.

Vermeulen, F. (2017, Nov.). Many Strategies Fail Because They're Not Actually Strategies. Harvard Business Review.

von Clausewitz, C. (2019, October 19). On War. https://www.gutenberg.org/files/1946/1946-h/1946-h.htm

Wardley, S. (2018). Wardley Mapping - Chapters 1-19. https://github.com/andrewharmellaw/wardley-mapsbook/releases/tag/0.19.1

Neil Kemp is an Enterprise Architect, working as a practitioner in disciplines related to strategy and the strategic design of enterprises, and enterprise information systems for forty years. Working with organisations of all sizes including in the multinational private and public sector, Mr Kemp has provided advice on the improvement and transformation of institutions to address issues of competitive capability and positioning, supply chain management, and the adoption of enterprise information systems (EIS) such as enterprise resource planning (ERP) and electronic commerce. As a proponent of "zero-based design", Mr Kemp continuously explores the application of repeatable and structured analysis of how the modern business can best approach its environment and exploit technology from a strategic perspective. 